\title{
Evaluation and case analysis of ecological garden city index
}

\author{
DELIGEER ${ }^{1, a}$, LI Yuan-yuan ${ }^{1, b}$ \\ ${ }^{1}$ College of Agriculture Science, Inner Mongolia Nationalities University, Tongliao 028043, Inner \\ Mongolia, China \\ a394063476@qq.com, b59556679@qq.com,
}

Keywords: Ecological garden; AHP; evaluation;

\begin{abstract}
Is the focus of attention from researchers with the high speed development of economy and the process of urbanization continues to accelerate, atmospheric pollution, ecological environment deterioration problems have become increasingly prominent, many cities have launched a ecological garden city to create the work, how to establish an effective evaluation index system. The on the basis of the original index system, according to the principles of evaluation of Ecological Garden City, the economic environment, ecological environment, environmental protection and infrastructure as the evaluation index, and uses the AHP to the weight distribution of the indicators. At the same time, take Qinhuangdao city as an example, the level of ecological garden construction is evaluated. The results show that the method is effective and has a certain persuasive power.
\end{abstract}

\section{Introduction}

Urbanization is the inevitable social and economic development, also brings a series of urban problems and environmental problems, has intensified the contradictions between human, resources, environment and urban ecological environment has been varying degrees of damage, the survival and development of human constitute a real threat. Therefore, how to maintain the sustainable development of the city, maintain the virtuous circle of the city's ecological environment, make the city and the natural coexist, and the harmony between man and nature become the important research subjects.[1-2]

The on the basis of existing ecological garden city standard evaluation, were further perfection and supplement, to build a new ecological garden city evaluation index system, and analysis to determine the weight of evaluation index system of evaluation index by using analytic hierarchy process. To Qinhuangdao ecological city as an example, the ecological garden city construction of comprehensive evaluation, analyzes the problems existing in the process of building, and combining with the actual situation, put forward feasible countermeasures and suggestions.

\section{Summary of ecological garden city}

The connotation of ecological garden city. Ecological garden city is a reasonable structure, functional efficiency and relationship coordination of urban ecosystem, is the development direction of landscape construction, is the indispensable important condition to realize the urban sustainable development, is on the basis of the garden city according to the characteristics of the urban landscape construction in China, to improve the urban ecological environment, promote the sustainable development of city of our country the new concept of urban construction. Ecological garden city the ecological and ornamental, sustainability, integrity, and regional characteristics, the natural conditions, people thought consciousness, the influence of factors such as urban construction situation [3-4].

\section{The principle of constructing ecological garden city.}

1. Adhere to the people-oriented principle

City is a highly populated area, so we are in the process of city construction must adhere to the principle of interest of residents, and shall adhere to sustainable development strategy, and do it 
with the person this, through our actual effort to build our city into a beautiful environment, the ecological balance of a comfortable, beautiful livable city.

2. Insist on the principle of environmental priorities

Beautiful environment can provide a good living environment, but also can attract more people to invest in our city employment, promote the development of the city. Therefore, we want to environmental protection in the urban construction as the key point, strive to build a city with beautiful environment, in order to promote the overall harmonious development of the city.

3. Adhere to the principle of adjust measures to local conditions

In the process of constructing ecological garden city we should stick to adjust measures to local conditions, starting from the practical principle, according to the ecological environment in different areas of the foundation to develop different development strategy. Around the ecological garden city construction activities and economic development are closely related, in the construction of ecological garden city, should avoid getting rich quick, and want to combine economic development around the set realistic goals, to promote coordinated development of economy, society and environment.

4. Adhere to the principle of urban and regional coordinated development

Ecological garden city create activity requires us to do urban and regional harmonious development, form the complete urban green space system, make the rational distribution of urban green space.

\section{Evaluation index system of ecological garden city construction}

Ecological garden city creation is a complex work, judge whether a city achieving ecological garden city standard requires us to establish a set of objective, suitable evaluation index system of ecological garden city, this will create and realize the city to promote the ecological garden city sustainable development play a positive role.

Select the evaluation index. According to the principle of the evaluation index system of Ecological Garden City, the economic environment, ecological environment, environmental protection, and infrastructure are the primary evaluation index. As shown in figure 1.

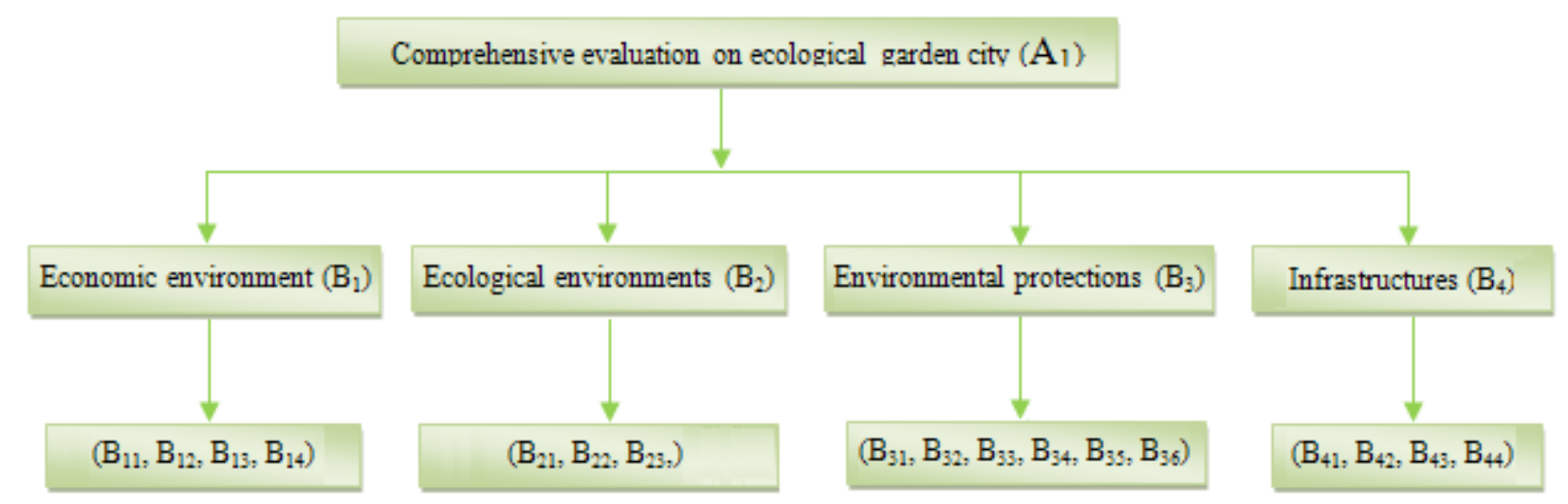

1. Economic environment

Including the per capita gross national product, third industry output value, per capita income per capita, disposable income.

2. Ecological environments

Including green coverage, built-up area green rate, per capita public green space.

3. Environmental protections

Including the air pollution index is less than 100 of the number of days, the urban water quality standards, the harmless treatment rate of domestic waste, industrial waste comprehensive utilization, motor vehicle environmental detection rate, comprehensive pollution index. 


\section{Infrastructures}

Including tap water, gas penetration, with public transport vehicles have a number of hospital beds, urban wastewater treatment rate.

\section{Determine the weights of evaluation indexes}

According to the degree of importance of each index will be divided into five levels, namely: very poor, poor, fair, good, very good [5]. Take the economic environment index, for example, the classification is shown in Table 1.

Tab.1 Evaluation criteria of ecological garden city

\begin{tabular}{c|c|c|c|c|c}
\hline \multirow{2}{*}{ Index } & \multicolumn{5}{c}{ Evaluation grade } \\
\cline { 2 - 6 } & very poor & poor & fair & good & very good \\
\hline $\begin{array}{c}\text { Proportion of third } \\
\text { industrialization (\%) }\end{array}$ & $25-30$ & $30-35$ & $35-40$ & $40-45$ & $45-50$ \\
\hline $\begin{array}{c}\text { Disposable income } \\
\text { (million) }\end{array}$ & $0.5-1.0$ & $1.0-1.5$ & $1.5-2.0$ & $2.0-2.5$ & $2.5-3.0$ \\
\hline $\begin{array}{c}\text { Real GDP per } \\
\text { capita (million) }\end{array}$ & $1.0-1.5$ & $1.5-2.0$ & $2.0-2.5$ & $2.5-3.0$ & $3.0-3.5$ \\
\hline $\begin{array}{c}\text { Per capita financial } \\
\text { income (million) }\end{array}$ & $0-0.5$ & $0.5-1.0$ & $1.0-1.5$ & $1.5-2.0$ & $2.0-2.5$ \\
\hline
\end{tabular}

Using analytic hierarchy process (AHP) to identify the complex problem is decomposed into a number of levels, by the experts and the decision makers of listed index are compared with each other, according to an important degree to judge score, using calculations to determine the eigenvectors of the matrix to determine the importance of lower index of the upper indexes to get evaluation indicators of the importance of the arrangement of the index weight. The steps are as follows [6]:

1. Build judgment matrix

$$
A=\left(a_{i j}\right), \quad a_{i j}>0
$$

2. Calculate index weight

$$
\begin{aligned}
M_{i} & =\prod_{i=1}^{n} a_{i j}, \quad i=1,2, \ldots, n \\
\overline{W_{i}} & =\sqrt[n]{M_{i}}, i=1,2,3 \ldots . ., n \\
W_{i} & =\overline{W_{i}} / \sum_{i=1}^{n} \overline{W_{i}} \\
\lambda_{\max } & =\sum_{i=1}^{n} \frac{(A W)_{i}}{n W_{i}}
\end{aligned}
$$

Where: $M_{i}$-Product matrix rows ; $W_{i}$ - Weight of index ;

$\lambda_{\max }-$ Maximum eigenvalues of a matrix.

According to the expert evaluation, the importance of first grade indexes from large to small in turn is: ecological environment index, environmental protection index, economic index, infrastructure indicators, the score results were substituted into the above formula to calculate the level indicators $\{\mathrm{B} 1, \mathrm{~B} 2, \mathrm{~B} 3, \mathrm{~B} 4\}$ weights for [0.196 and 0.451, 0.266, 0.087]. Similarly, the weights of the two levels are determined by using the analytic hierarchy process. In economic 
environment, for example, composed of four secondary indexes, through expert scoring and comes to the conclusion that the degree of importance of the four secondary indexes from big to small is in turn: the proportion of the third industry, per capita disposable income, per capita income, per capita gross national product, in accordance with the method of determine the weights of the four secondary indexes. As shown in table 2.

Tab.2 Weight of the economic environment

\begin{tabular}{ccccc}
\hline $\mathrm{B}_{1}$ & $\mathrm{~B}_{11}$ & $\mathrm{~B}_{12}$ & $\mathrm{~B}_{13}$ & $\mathrm{~B}_{14}$ \\
\hline $\mathrm{B}_{11}$ & 1 & 5 & 3 & 5 \\
$\mathrm{~B}_{12}$ & $1 / 5$ & 1 & $1 / 5$ & $1 / 3$ \\
$\mathrm{~B}_{13}$ & $1 / 3$ & 5 & 1 & 3 \\
$\mathrm{~B}_{14}$ & $1 / 5$ & 3 & $1 / 3$ & 1 \\
Weight & 0.075 & 0.576 & 0.105 & 0.244 \\
\hline
\end{tabular}

\section{Case analysis}

In order to evaluate the effectiveness of the evaluation method, the city of Qinhuangdao as an example, the level of ecological garden construction in 2008 -2010 was evaluated, the results were shown in Table 3.

Tab.3 Evaluation results of ecological garden cityfrom2008to2010in Qinhuangdao

\begin{tabular}{|c|c|c|c|c|c|c|c|}
\hline Years & Index & very poor & poor & fair & good & very good & $\begin{array}{c}\text { Evaluation } \\
\text { results }\end{array}$ \\
\hline \multirow{4}{*}{2008} & $\begin{array}{c}\text { Economic } \\
\text { Environment }\end{array}$ & 0.000 & 0.092 & 0.088 & 0.000 & 0.008 & \multirow{4}{*}{ poor } \\
\hline & $\begin{array}{c}\text { Ecological } \\
\text { Environment }\end{array}$ & 0.000 & 0.000 & 0.000 & 0.000 & 0.000 & \\
\hline & $\begin{array}{c}\text { Environmental } \\
\text { Protection }\end{array}$ & 0.000 & 0.023 & 0.015 & 0.042 & 0.041 & \\
\hline & Infrastructure & 0.003 & 0.000 & 0.000 & 0.000 & 0.029 & \\
\hline \multirow{4}{*}{2009} & $\begin{array}{c}\text { Economic } \\
\text { Environment }\end{array}$ & 0.000 & 0.039 & 0.000 & 0.035 & 0.009 & \multirow{4}{*}{ fair } \\
\hline & $\begin{array}{c}\text { Ecological } \\
\text { Environment }\end{array}$ & 0.000 & 0.000 & 0.000 & 0.000 & 0.000 & \\
\hline & $\begin{array}{c}\text { Environmental } \\
\text { Protection }\end{array}$ & 0.000 & 0.000 & 0.066 & 0.016 & 0.025 & \\
\hline & Infrastructure & 0.006 & 0.000 & 0.000 & 0.000 & 0.029 & \\
\hline \multirow{4}{*}{2010} & $\begin{array}{c}\text { Economic } \\
\text { Environment }\end{array}$ & 0.000 & 0.000 & 0.012 & 0.054 & 0.010 & \multirow{4}{*}{ good } \\
\hline & $\begin{array}{c}\text { Ecological } \\
\text { Environment }\end{array}$ & 0.011 & 0.000 & 0.000 & 0.000 & 0.000 & \\
\hline & $\begin{array}{c}\text { Environmental } \\
\text { Protection }\end{array}$ & 0.000 & 0.000 & 0.000 & 0.023 & 0.030 & \\
\hline & Infrastructure & 0.000 & 0.001 & 0.000 & 0.000 & 0.033 & \\
\hline
\end{tabular}

From the comprehensive evaluation results can be seen, Qinhuangdao 2008-2010 construction of ecological garden city comprehensive evaluation results by changing the poor is better, and has made great achievements in the economic environment, ecological environment, environmental protection, infrastructure, ecological garden city construction on the to a new level. Although in Qinhuangdao City in the construction of ecological garden has made some achievements, but the distance there is a certain gap between the standard of national ecological garden city, industrial 
structure is unreasonable, urban air pollution is serious, medical system is not perfect, and many problems still exist and should be further improved.

\section{Conclusion}

1. In view of the problems existing in the present ecological garden city evaluation index system, the economic environment, ecological environment, environmental protection, and infrastructure for first grade indexes, application level analysis and other methods of each index weight analysis, so as to establish a new evaluation index system.

2. In Qinhuangdao City as an example, used to construct the evaluation method for 2008 to 2010 ecological landscape construction level evaluation, according to the evaluation results, find out the problems existing in the construction of the ecological landscape of the city and to provide reference for improving the construction level of urban landscape architecture.

\section{References}

[1] Makoto kiyota .London Planning Advisory Committee 1992 Open space planning in London London: ArtiJlery House. 2002,(43):67

[2] Xu Y N, Jia D P.Wang X. The study of green space system planning based on AHP and GIS in Changzhou city, China [C], In:2009 $2^{\text {nd }}$ International Conference on Information and Computing Science, Manchester, United kingdom, 2009, 405-408.

[3] Timo Pukkala.Tuula Nulltinen. Jyrki Kangas.1995. Integrating scenic and recreational amenities Into numerical forest Planning [J]. Lalldscape and Urban Planning, 2006.(32): 185 195

[4] Paseua-Horta L, Saura S. Impact of spatial scale on the identification of critical habitat patches for the maintenance of landscape connectivity [J]. Landscape and Urban Planning, 2007, 83:176-186.

[5] Julius, G. Fabos. Greenway planning in the United Status's origins and recent case Studies[J].Landscape and Urban Planning,2004,(68):321 342

[6] Simon U, Bruggemann R, Pudenz S. Aspects of decision support in water managementexample Berlin and Potsdam (Germany) I-spatially differentiated evaluation. Water Research, 2004, 38(7): 1809-1816. 